\title{
Influence of EGFR mutational status on metastatic behavior in non squamous non small cell lung cancer
}

\author{
Alessandro Russo ${ }^{1}$, Tindara Franchina ${ }^{1}$, Giuseppina Rosaria Rita Ricciardi ${ }^{1}$, \\ Caterina Fanizza ${ }^{2}$, Antonino Scimone ${ }^{1}$, Giuseppe Chiofalo ${ }^{1}$, Antonio Giordano ${ }^{3,4}$, \\ Vincenzo Adamo ${ }^{1}$ \\ ${ }^{1}$ Medical Oncology Unit A.O. Papardo \& Department of Human Pathology University of Messina, Italy \\ ${ }^{2}$ Fondazione Mario Negri Sud, Santa Maria Imbaro, Chieti, Italy \\ ${ }^{3}$ Department of Medicine, Surgery and Neuroscience, University of Siena and Istituto Toscano Tumori (ITT), Siena, Italy \\ ${ }^{4}$ Sbarro Institute for Cancer Research and Molecular Medicine, Center for Biotechnology, College of Science and Technology, \\ Temple University, Philadelphia PA, USA \\ Correspondence to: Vincenzo Adamo, email: vadamo@unime.it \\ Keywords: NSCLC, EGFR mutations, metastatic spread, EGFR WT, brain metastases \\ Received: November 10,2016 Accepted: December 01,2016 Published: January 02, 2017
}

\section{ABSTRACT}

Epidermal Growth Factor Receptor (EGFR) mutated Non Small Cell Lung Cancers (NSCLCs) are a molecularly subgroup of patients with peculiar clinic-pathological characteristics. Previous studies have suggested a possible interaction between oncogene status and metastatic behavior in non squamous NSCLCs with conflicting results. The aim of this study was to compare the different metastatic patterns, at baseline and during the course of the disease, in a cohort of 137 Caucasian patients with non-squamous NSCLC according to the EGFR mutational status and survival differences according to the different metastatic behavior. We observed unique metastatic distributions between EGFR-mutated and EGFR wild type non-squamous NSCLCs. These data support the hypothesis that tumor bio-molecular characteristics and genotype may influence the metastatic process in NSCLC and might help the development of enrichment strategies for tumor genotyping in these tumors, especially in the presence of limited tissue availability.

\section{INTRODUCTION}

Lung cancer is the leading cause of cancer-related death among males in both more and less developed countries, and has surpassed breast cancer as the leading cause of cancer death among females in more developed countries [1]. Non Small Cell Lung Cancer (NSCLC) accounts for approximately $80 \%$ of the cases, with adenocarcinoma as the most commonly observed subtype. During the last decade the therapeutic landscape of NSCLC has been profoundly changed with the discovery of Epidermal Growth Factor Receptor (EGFR) mutations and the clinical demonstration of superiority of EGFR Tyrosine Kinase Inhibitors (TKIs) over chemotherapy in molecularly selected NSCLCs [2]. The identification of EGFR mutations has paved the way to the discovery of additional targetable oncogenes with a growing list of emerging molecularly defined subtypes [3], which approximately $60 \%$ of adenocarcinomas having a known activating mutation [4].

EGFR mutated NSCLC is a molecularly defined tumor subtype ( $15-20 \%$ of adenocarcinomas of the lung) with peculiar clinic-pathological features: Asian ethnicity, female sex, adenocarcinoma histology and never smoking status $[2,5,6]$.

Metastatic distributions in NSCLCs may be influenced by several factors, including tumor histology [7] and oncogene status $[8,9]$.

Some authors have hypothesized a possible association between metastatic distribution and oncogene status, with peculiar patterns of metastatization among oncogene addicted NSCLCs, suggesting that biology may drive metastasis in NSCLC $[8,9]$. For instance, EGFR-mutated NSCLCs may present a different metastatic behavior compared with wild type tumors: more frequent liver involvement at diagnosis [8], higher incidence of BMs at baseline 
[10] and/or during the course of the disease [11-15] or finally a higher tendency to develop diffuse/miliary pulmonary metastases $[10,16]$. Recently, Ochiai S, et al. suggested that EGFR mutational status may also influence the recurrence pattern after definitive chemoradiotherapy in locally-advanced NSCLC, with a higher prevalence of distant recurrences among EGFR mutated tumors, compared with EGFR wild type, which instead experience higher loco-regional failures [14].

Some Authors have also reported a correlation between the specific type of EGFR mutations and peculiar patterns of metastatization, with a higher tendency to develop multiple, diffuse, small brain metastases with small peritumoral edema in patients with exon 19 deletions [17].

However, other Authors did not find any statistical difference in the development of brain and bone metastases [9] or in the number, neuroanatomical location or size of BMs between EGFR-mutated and EGFR WT tumors [18].

Moreover, patients with genetic rearrangements, such as ALK- and ROS1-traslocated tumors, seemed to be associated with peculiar metastatization patterns. Indeed, some Authors have reported a higher tendency to develop BMs among ALK-rearranged NSCLCs [19], which in some instances might be associated with specific radiological patterns, such as miliary distribution [20] or cystic lesions [21, 22]. Moreover, others have reported specific radiographic features [23-25] and bronchoscopic findings in EGFR mutated NSCLCs [26].

In 2012 Doebele et al. first reported the evidence of a different metastatic behavior among oncogene-addicted NSCLCs compared with wild type tumors [8]. ALKpositive tumors presented a higher prevalence of pleural and/or pericardial involvement and a higher number of metastatic lesions compared with other molecularly defined subgroups (EGFR and KRAS mutated NSCLCs) and with "triple negative" tumors (i.e. wild type tumors for EGFR, KRAS and ALK). Moreover, ALK rearranged NSCLCs presented a higher involvement in less common metastatic sites, such as retinal metastases. Interestingly, they also reported a higher incidence of liver metastases in EGFR mutated NSCLCs compared with "triple negative" tumors. Moreover, oncogene-addicted tumors may occasionally seemed to be more prone to develop metastases in unusual sites of metastatization, such as retinal [8] and intramedullary metastases in ALKrearranged tumors [27] or ovarian metastases in ROS1traslocated NSCLCs [28].

The aim of this study was to compare the different metastatic patterns, at baseline and during the course of the disease, in a cohort of Caucasian patients with nonsquamous NSCLC according to the EGFR mutational status and survival differences according to the different metastatic behavior.

\section{RESULTS}

We analyzed the distribution of metastatic sites of our patient cohort at baseline. The number of metastatic sites at baseline was not statistically different between EGFR mutated and EGFR wild type tumors $(\mathrm{p}=0.61)$. Although not statistically significant, there was a trend favoring specific patterns of metastatization among EGFR mutated NSCLCs compared with wild type tumors, including a tendency to develop at baseline more frequently brain metastases $(p=0.12)$, lung metastases $(p=0.14)$, pleural involvement $(p=0.17)$, and bone metastases $(p=0.31)$ [Figure 1].

Brain metastases (BMs) were detected at baseline in 32 patients (23.36\%), 5 with EGFR mutations and 27 EGFR wild type (13.89 and $26.73 \%$, respectively). Of all 137 patients, 47 patients (34\%) developed BMs and EGFRmutated NSCLCs seemed more prone to develop brain metastases during the course of their disease compared with wild type tumors, albeit this difference was not statistically significant $(p=0.31)$. Moreover, CNS involvement in EGFR-mutated patients tended to be associated with multiple brain metastases ( $\geq 4$ lesions) $(p=0.63$ ). Interestingly, patients receiving an EGFR TKI (namely, Erlotinib, Gefitinib or Afatinib) developed more frequently BMs compared with those receiving chemotherapy and this difference was statistically significant $(p=0.048)$.

Treatment of BMs is reported in Table 1.

EGFR wild type patients had shorter overall survival (OS) compared with those carrying an EGFR mutation: median OS [95\% CI]: 9.97 months [6.95; 18.00] vs. 19.18 months $[7.02 ; 28.95]$. As expected, this difference was statistical significant: HR [95\% CI], p value 1.48 [0.91; 2.39], $p=0.11$ [Figure 2].

EGFR mutations were associated with an improved OS even in patients with BMs, since patients harboring an EGFR mutation presented a longer OS compared with those with EGFR wild type NSCLCs: median OS [95\% CI] 8.72 months [0.46; 99.31] vs. 4.10 months [2.98; 10.10]. The difference between the two subgroups was statistically significant: $\mathrm{HR}[95 \% \mathrm{CI}], \mathrm{p}$ value 1.72 [0.74; 3.96], $p=0.21$ [Figure 3].

\section{DISCUSSION}

In the present study, we aimed to compare the patterns of metastases at initial diagnosis and during the course of the disease according to the EGFR mutational status in advanced non-squamous NSCLCs. A total of 137 Caucasian non-squamous NSCLC patients were included in this analysis. Metastatic distributions differed between EGFR mutated and EGFR wild type tumors. Albeit not statistically significant, EGFR mutated NSCLCs tended to develop at baseline, with a higher frequency compared with wild type tumors, brain metastases $(p=0.12)$, lung 
metastases $(p=0.14)$, pleural involvement $(p=0.17)$, and bone metastases $(p=0.31)$ [Figure 1]. No statistical differences were noted in the number of metastatic sites at baseline between the groups $(p=0.60)$.

Median overall survival, as expected was significantly longer among EGFR mutated NSCLCs (19.18 months [7.02; 28.95] vs. 9.97 months [6.95; 18.00]) and is comparable with that reported in Caucasian patients carrying EGFR mutations treated with first generation EGFR TKIs [29, 30].

We also evaluated the impact of brain metastases emergence at baseline and during the disease course according to the EGFR mutational status and the use of EGFR TKIs. We did not found a statistically significant different distribution to the CNS between EGFR wild type and EGFR mutated NSCLCs, albeit a higher tendency to brain metastatization was observed among EGFR mutated patients $(p=0.31)$. The association between BMs emergence and EGFR mutational status has produced contrasting results in literature. Mak et al. retrospectively evaluated medical records of 525 NSCLC patients with BMs treated with radiotherapy, of whom 172 underwent tumor genotyping. Oncogene status did not predict CNS involvement and did not influence number, neuroanatomic location, or size of brain metastases [18]. However, others reported a positive correlation between EGFR mutational status and brain metastases emergence [10, 14, 15, 25] and a tendency to the development of multiple lesions [10]. Moreover, Ochiai et al. recently reported a higher prevalence of distant recurrences, mainly BMs, among EGFR mutated tumors, compared with EGFR wild type, after definitive chemoradiotherapy in stage III NSCLC [14].

In the present study, EGFR mutated NSCLCs seemed to develop more frequently multiple brain metastases compared with wild type tumors, although this difference did not reach statistical significant ( $p=$ $0.16)$ likely due to the small sample size. Moreover, EGFR mutational status was a positive prognostic factor among patients with brain metastases, since EGFR mutated NSCLCs with BMs lived longer than wild type counterparts: median OS [95\% CI] 8.72 months [0.46; 99.31] vs. 4.10 months $[2.98 ; 10.10]$; $\mathrm{HR}[95 \% \mathrm{CI}]$, $\mathrm{p}$ value $1.72[0.74 ; 3.96], p=0.21$ [Figure 3]. A recent large prospective observational study in European patients showed a median OS of 7.2 months [95\% confidence interval (CI) 6.1-8.2] for patients with brain metastases

\section{Metastatic pattern at Baseline}

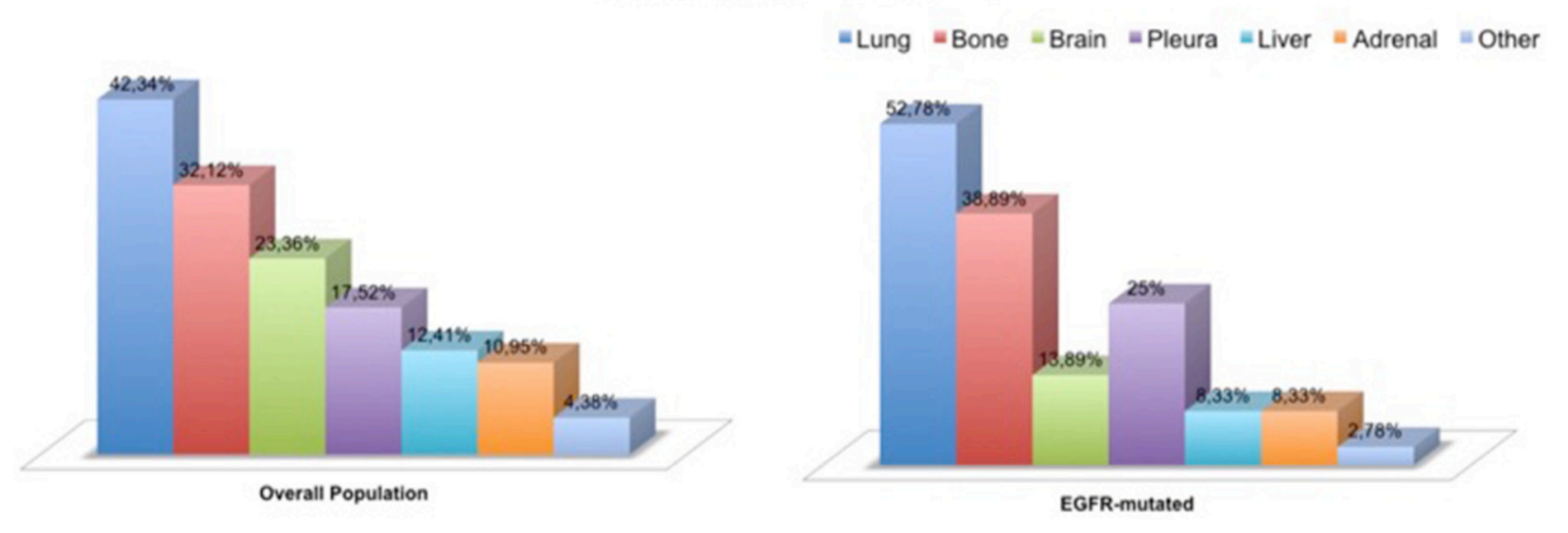

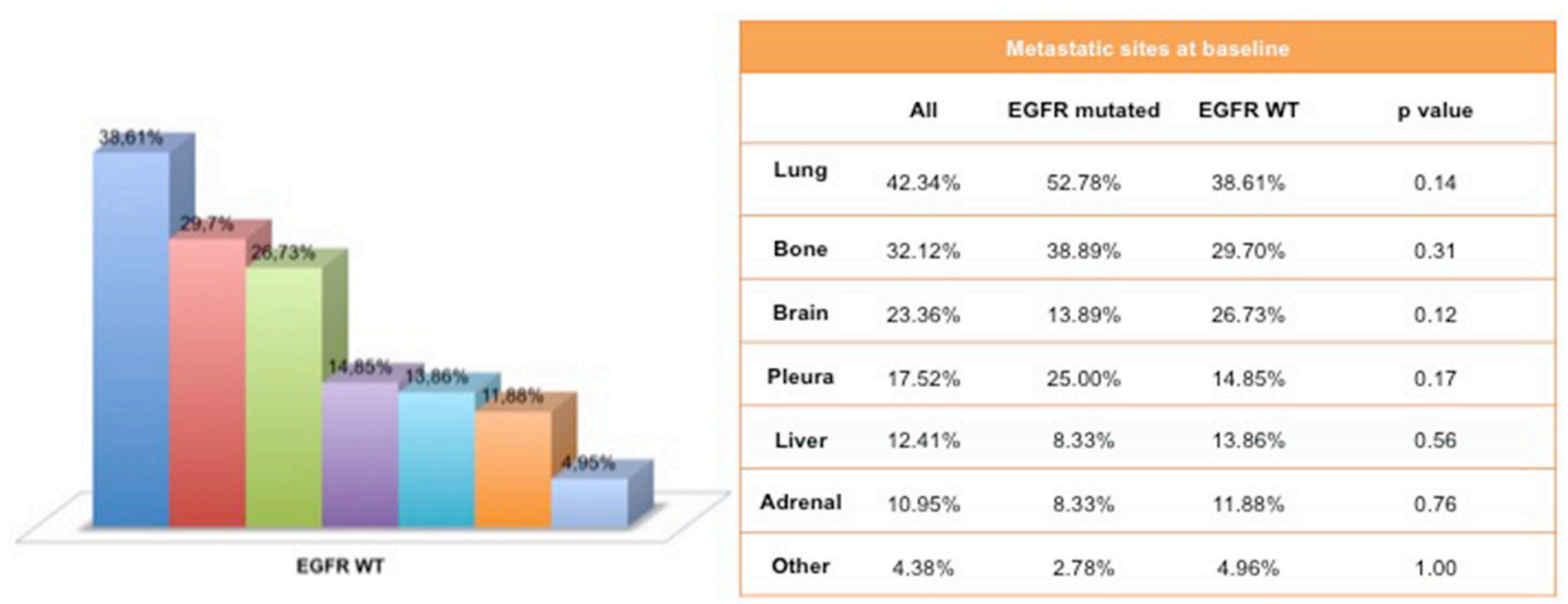

Figure 1: Metastatic pattern at baseline according to the EGFR mutational status. 
Table 1. Loco-regional treatments in patients with brain metastases according to the EGFR mutational status. Legend: SRS, stereotactic radiotherapy; WBRT, whole brain radiotherapy

All (\%) EGFR-mutated EGFR WT (\%)

(\%)

\begin{tabular}{lccc}
\hline Patients with BMs undergoing loco-regional treatment(s) & $36(76.60)$ & $8(80.00)$ & $28(75.68)$ \\
\hline $\begin{array}{l}\text { Loco-regional treatment(s) modalities } \\
\quad \text { Radiotherapy }\end{array}$ & $33(91.67)$ & $8(100.00)$ & $25(89.29)$ \\
$\quad$ Surgery & $1(2.78)$ & $0(0.00)$ & $1(3.57)$ \\
$\quad$ Radiotherapy + Surgery & $2(5.56)$ & $0(0.00)$ & $2(7.14)$ \\
Radiotherapy modalities & & & \\
\hline SRS & $5(14.29)$ & $2(25.00)$ & $3(11.11)$ \\
WBRT & $25(71.42)$ & $6(75.00)$ & $19(70.37)$ \\
$\quad$ SRS + WBRT & $5(14.29)$ & $0(0.00)$ & $5(18.52)$ \\
\hline
\end{tabular}

treated with first-line platinum-based chemotherapy [31]. EGFR mutational status is a significant prognostic factor in patients with BMs, since EGFR mutated NSCLCs with BMs seems to experience longer survival compared with wild type tumors $[12,15,32]$.

The positive prognostic role of EGFR mutations is likely due to the higher intracranial response rates observed with EGFR TKIs, a better extra-cranial disease control and, finally, an increased sensitivity to locoregional treatments, such as WBRT and SRS [33-36].

However, the emergence of BMs still remains a negative prognostic factor even in EGFR mutated patients treated with an EGFR TKI and it is associated with a shorter OS [37]. These data are in line with our results, since EGFR mutated patients developing BMs during the course of their disease experienced a shorter OS compared with the overall EGFR mutated population (8.72 vs. 19.18 months, respectively).

Several studies have reported a positive impact of EGFR TKIs on BMs. EGFR mutated NSCLCs treated with an EGFR TKI may experience high intracranial ORR (60-100\% ORR, $40 \% \mathrm{CR})[38,39]$ and show lower rates of CNS progression compared with those treated with upfront chemotherapy [40]. In patients with asymptomatic BMs at baseline and EGFR mutations WBRT may be differed, since radiotherapy did not impact OS [41, 42] and first-line EGFR TKIs are associated with clinical activity against both intracranial and extracranial lesions [43]. Recently, the results of the phase III trial QUARZ [44] suggested that WBRT in patients with NSCLC and BMs unsuitable for surgical resection or stereotactic radiotherapy provide little clinical benefit compared with best supportive care alone.

The concomitant use of radiotherapy on brain metastases and EGFR TKIs is safe and is associated with improved outcomes [45, 46]. However, a recent retrospective analysis suggests that the use of upfront radiotherapy followed by EGFR TKI therapy among EGFR mutated NSCLCs with BMs is associated with increased OS when using SRS, but not WBRT. Moreover, upfront radiotherapy seems to prolong intracranial PFS compared with upfront EGFR TKI [47].

A few studies have suggested that patients carrying an EGFR activating mutation may present a higher frequency of pulmonary, multiple, bilateral metastases $[16,23]$. Likely to the small sample size, we failed to demonstrate a statistically significant difference between EGFR mutated and wild type NSCLCs, albeit a positive trend favoring an increased tendency to lung metastatization was observed $(p=0.14)$,

We recognize that our present analysis has some limitations. The inherited retrospective nature of our study and the lack of further stratification of EGFR wild type patients might be possible biases of our analysis. Indeed, we recognize that EGFR wild type tumors are a heterogeneous subgroup of NSCLCs with several potential driver mutations. However, the relative low frequency of these mutations and the small sample size of the study did not allow a further characterization based on additional oncogenes and do not affect the present analysis.

Routine molecular profiling on a regional/ national base is feasible as demonstrated in the Lung Cancer Mutational Consortium (LCMC) [48] and in the Biomarkers France study [49] and may orient patients towards personalized therapies, overcoming the limits of single institutions, in terms of genetic tests performed and clinical trial availability.

In conclusion, we observed unique metastatic distributions between EGFR-mutated and EGFR wild type non-squamous NSCLCs in a cohort of 137 Caucasian patients with non squamous NSCLC. These data support the hypothesis that tumor bio-molecular characteristics and genotype may influence the metastatic process in NSCLC and might help the development of enrichment 


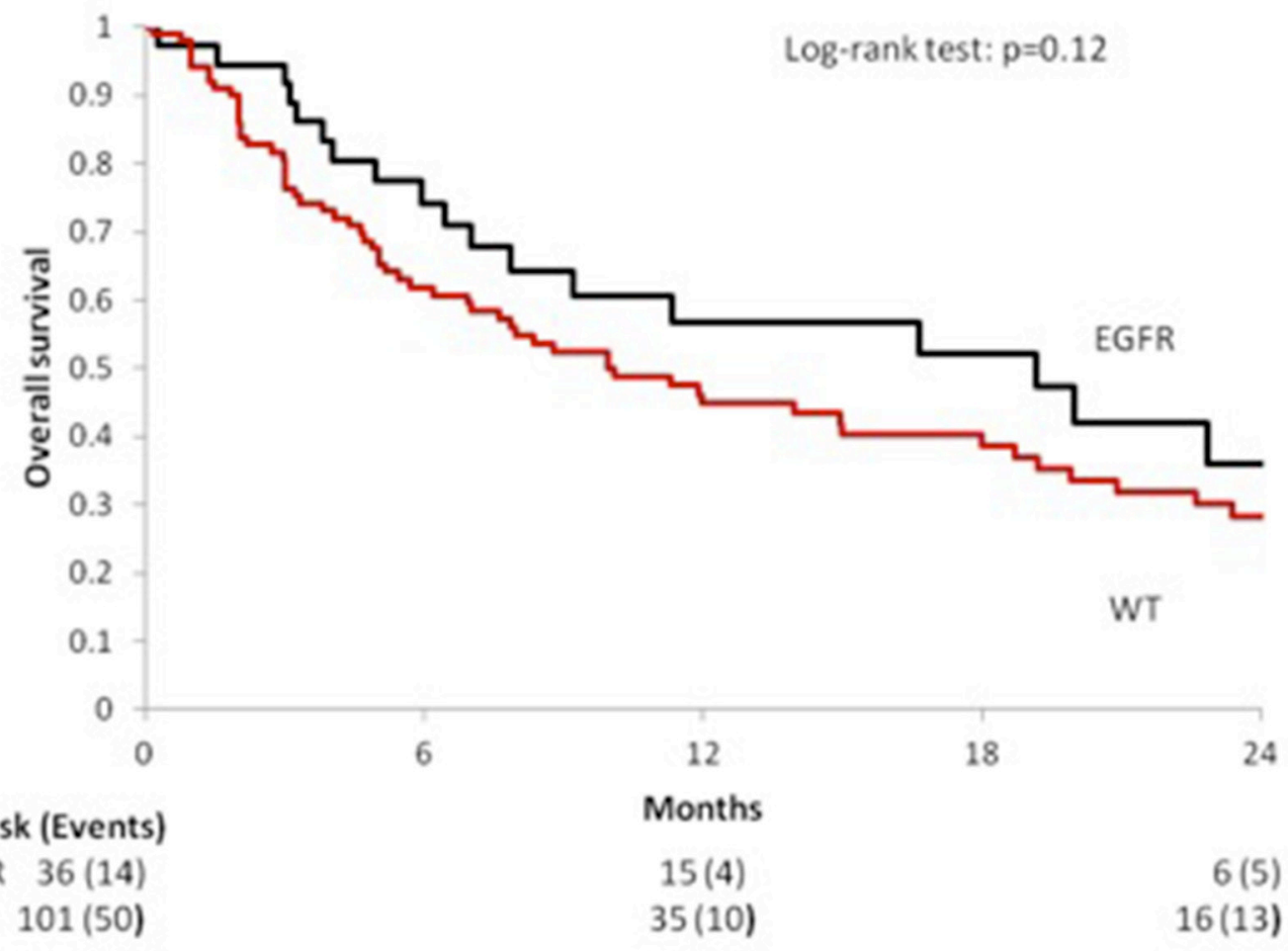

Figure 2: Median OS according to the EGFR mutational status in the overall population.

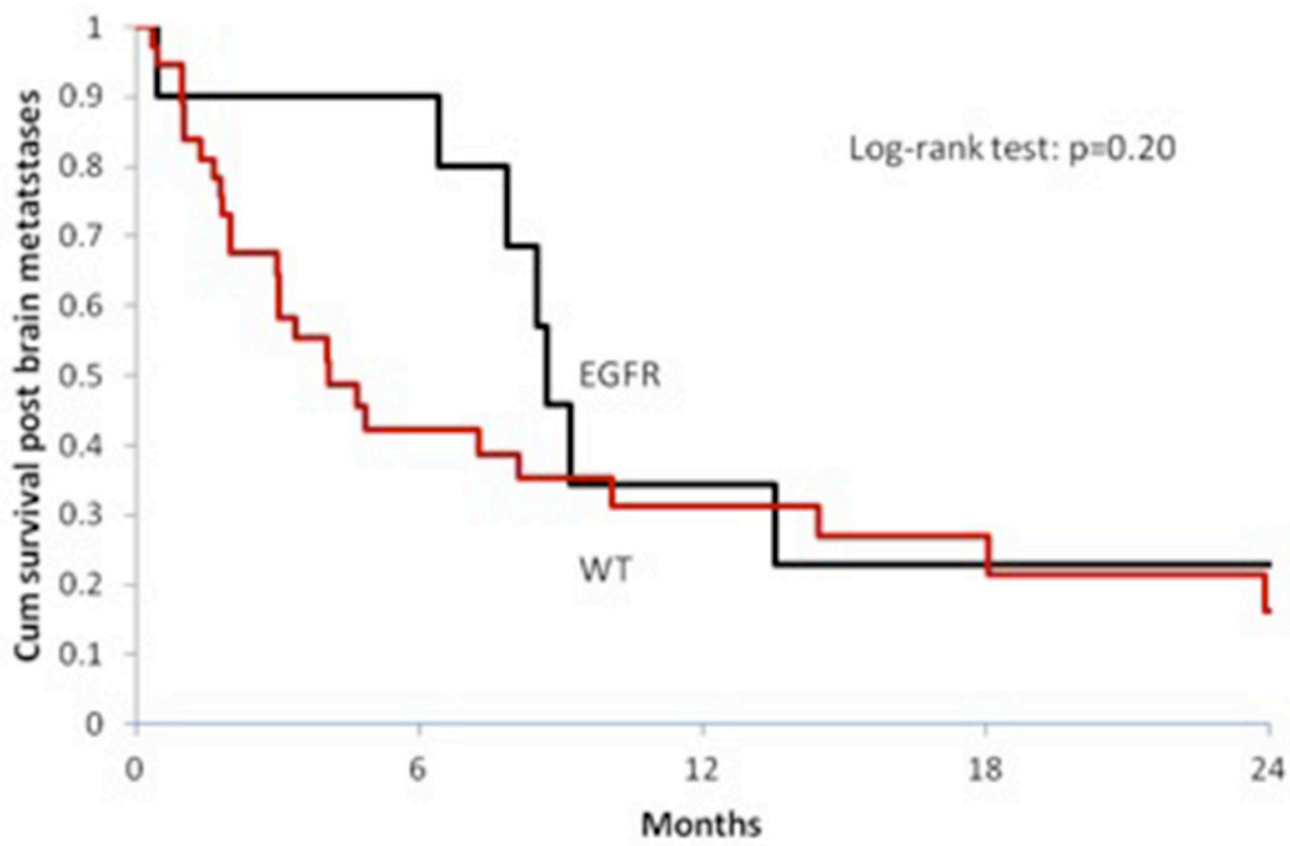

At Risk (Events)

EGFR $10(3)$

$3(2)$

WT $37(20)$

$8(3)$

$1(3)$

$3(6)$

Figure 3: Median OS in patients with Brain Metastases (BMs) according to the EGFR mutational status. 
Table 2. Baseline characteristics of patients included in the study

\begin{tabular}{|c|c|c|c|c|}
\hline Variables & N. & EGFR-mutated & EGFR WT & p value \\
\hline & 137 & $36(26.3 \%)$ & $101(73.7 \%)$ & \\
\hline Median age & $66.23 \pm 10.53$ & $67.94 \pm 12.86$ & $65.62 \pm 9.56$ & 0.06 \\
\hline Sex & & & & 0.91 \\
\hline M & $81(59.12 \%)$ & $21(58.33 \%)$ & $60(59.41 \%)$ & \\
\hline $\mathrm{F}$ & $56(40.88 \%)$ & $15(41.67 \%)$ & $41(40.59 \%)$ & \\
\hline Smoking Status & & & & 0.002 \\
\hline Current smoker & $38(27.74 \%)$ & $3(8.33 \%)$ & $35(34.65 \%)$ & \\
\hline Former Smoker & $68(49.64 \%)$ & $21(58.33 \%)$ & $47(46.53 \%)$ & \\
\hline Never smoker & $26(18.98 \%)$ & $12(33.33 \%)$ & $14(13.86 \%)$ & \\
\hline Unknown & $5(3.56 \%)$ & $0(0.00 \%)$ & $5(4.95 \%)$ & \\
\hline Histology & & & & 0.33 \\
\hline Adenocarcinoma & $100(72.99 \%)$ & $29(80.56 \%)$ & $71(70.30 \%)$ & \\
\hline Adeno-squamous & $11(8.03 \%)$ & $1(2.87 \%)$ & $10(9.90 \%)$ & \\
\hline NOS & $26(18.98 \%)$ & $6(16.67 \%)$ & $20(19.80 \%)$ & \\
\hline
\end{tabular}

strategies for tumor genotyping in these tumors, especially in the presence of limited tissue availability. Further development of our study will include the enlargement of the original cohort and extension of genetic determinants analyzed the in order to allow a better characterization of EGFR wild type subgroup.

\section{PATIENTS AND METHODS}

We retrospectively evaluated medical records of 137 consecutive patients with advanced/metastatic nonsquamous NSCLC treated at our Institution from January 2013 to November 2015. Baseline characteristics are summarized in Table 2.

Inclusion criteria: age $>18$ years; cytological and/or pathological confirmed non-squamous NSCLC; stage IIIB or IV (recurrent or metastatic) according to according to TNM [tumor, node, metastasis] American Joint Committee on Cancer [AJCC] version VII; availability of the EGFR mutational status.

Patients were prospectively genotyped using tumor specimens from diagnostic or surgical procedures. EGFR mutational status was determined by real time PCR with a validated test kit (TheraScreen EGFR 29 [TheraScreen29]; Qiagen, Manchester, UK).

Molecular testing was performed according to the ASCO/CAP guidelines [50].

Metastatic sites of every single patient were analyzed at baseline and during the course of the disease.

Categorical variables were presented as proportions, and continuous variables as means (standard deviation) or medians (Q1-Q3), based on the normality of distribution by the Kolmogorov-Smirnov test. Categorical variables were compared using chi-square or Fisher's exact test, continuous variables were compared using Student's $t$ or the Mann-Whitney nonparametric U test. OS was defined as time from diagnosis of metastatic NSCLC to death and post brain metastases survival was calculated from diagnosis of these metastases to death (patients without event were censored at last visit). Both were estimated using the Kaplan-Meier method. Survival curves were compared using the log-rank test. To estimate the hazard ratio (HR), Cox regression analysis was used. Statistical analyses were performed with the R program.

\section{Abbreviations}

AJCC: American Joint Committee on Cancer

ALK: Anaplastic Lymphoma Kinase

BMs: Brain Metastases

CNS: Central Nervous System

EGFR: Epidermal Growth Factor Receptor

HR: Hazard Ratio

LCMC: Lung Cancer Mutational Consortium

NOS: Non Otherwise Specified

NSCLC: Non small Cell Lung Cancer

PCR: Polymerase Chain Reaction

ROS1: c-ros oncogene 1

TKIs: Tyrosine Kinase Inhibitors

TNM: Tumor, Node, Metastasis

WBRT: Whole Brain Radiotherapy

WT: Wild Type

\section{CONFLICTS OF INTEREST}

no potential conflicts of interest declared. 


\section{GRANT SUPPORT}

This work was supported by the Consorzio Interuniversitario Nazionale per la Bio-Oncologia (CINBO) and A.S.S.O. (Associazione Siciliana Sostegno Oncologico) Onlus.

\section{REFERENCES}

1. Torre LA, Bray F, Siegel RL, Ferlay J, Lortet-Tieulent J, Jemal A. Global cancer statistics, 2012. CA Cancer J Clin. 2015; 65:87-108.

2. Russo A, Franchina T, Ricciardi GR, Picone A, Ferraro G, Zanghì M, Toscano G, Giordano A, Adamo V. A decade of EGFR inhibition in EGFR-mutated non small cell lung cancer (NSCLC): Old successes and future perspectives. Oncotarget. 2015; 6:26814-25. doi: 10.18632/ oncotarget.4254.

3. Oxnard GR, Binder A, Jänne PA. New targetable oncogenes in non-small-cell lung cancer. J Clin Oncol. 2013; 31:1097-104.

4. Cancer Genome Atlas Research Network. Comprehensive molecular profiling of lung adenocarcinoma. Nature. 2014; 511:543-50.

5. Gerber DE, Gandhi L, Costa DB. Management and future directions in non-small cell lung cancer with known activating mutations. Am Soc Clin Oncol Educ Book. 2014:e353-65.

6. Zhang YL, Yuan JQ, Wang KF, Fu XH, Han XR, Threapleton D, Yang ZY, Mao C, Tang JL. The prevalence of EGFR mutation in patients with non-small cell lung cancer: a systematic review and meta-analysis. Oncotarget. 2016; 7:78985-78993. doi: 10.18632/oncotarget.12587.

7. Lee DS, Kim YS, Kay CS, Kim SH, Yeo CD, Kim JW, Kim SJ, Kim YK, Ko YH, Kang JH, Lee KY. Distinctive Patterns of Initially Presenting Metastases and Clinical Outcomes According to the Histological Subtypes in Stage IV NonSmall Cell Lung Cancer. Medicine (Baltimore). 2016; 95:e2795.

8. Doebele RC, Lu X, Sumey C, Maxson DA, Weickhardt AJ, Oton AB, Bunn PA Jr, Barón AE, Franklin WA, Aisner DL, Varella-Garcia M, Camidge DR. Oncogene status predicts patterns of metastatic spread in treatment-naive nonsmall cell lung cancer. Cancer. 2012; 118:4502-11.

9. Hendriks LE, Smit EF, Vosse BA, Mellema WW, Heideman DA, Bootsma GP, Westenend M, Pitz C, de Vries GJ, Houben R, Grünberg K, Bendek M, Speel EJ, et al. EGFR mutated non-small cell lung cancer patients: more prone to development of bone and brain metastases? Lung Cancer. 2014; 84:86-91.

10. Shin DY, Na II, Kim CH, Park S, Baek H, Yang SH. EGFR mutation and brain metastasis in pulmonary adenocarcinomas. J Thorac Oncol. 2014; 9:195-9.
11. Matsumoto S, Takahashi K, Iwakawa R, Matsuno Y, Nakanishi Y, Kohno T, Shimizu E, Yokota J. Frequent EGFR mutations in brain metastases of lung adenocarcinoma. Int $\mathrm{J}$ Cancer. 2006; 119:1491-4.

12. Eichler AF, Kahle KT, Wang DL, Joshi VA, Willers H, Engelman JA, Lynch TJ, Sequist LV. EGFR mutation status and survival after diagnosis of brain metastasis in nonsmall cell lung cancer. Neuro Oncol. 2010; 12:1193-9.

13. Welsh JW, Komaki R, Amini A, Munsell MF, Unger W, Allen PK, Chang JY, Wefel JS, McGovern SL, Garland LL, Chen SS, Holt J, Liao Z, et al. Phase II trial of erlotinib plus concurrent whole-brain radiation therapy for patients with brain metastases from non-small-cell lung cancer. J Clin Oncol. 2013; 31:895-902.

14. Ochiai S, Nomoto Y, Watanabe Y, Yamashita Y, Toyomasu Y, Kawamura T, Takada A, Noriko, Sakuma H. The impact of epidermal growth factor receptor mutations on patterns of disease recurrence after chemoradiotherapy for locally advanced non-small cell lung cancer: a literature review and pooled analysis. J Radiat Res. 2016; 57:449-459.

15. Han G, Bi J, Tan W, Wei X, Wang X, Ying X, Guo X, Zhou $\mathrm{X}, \mathrm{Hu} \mathrm{D}$, Zhen $\mathrm{W}$. A retrospective analysis in patients with EGFR-mutant lung adenocarcinoma: is EGFR mutation associated with a higher incidence of brain metastasis? Oncotarget. 2016; 7:56998-57010. doi: 10.18632/oncotarget. 10933.

16. Togashi Y, Masago K, Kubo T, Sakamori Y, Kim YH, Hatachi Y, Fukuhara A, Mio T, Togashi K, Mishima M. Association of diffuse, random pulmonary metastases, including miliary metastases, with epidermal growth factor receptor mutations in lung adenocarcinoma. Cancer. 2011; 117:819-25.

17. Sekine A, Kato T, Hagiwara E, Shinohara T, Komagata T, Iwasawa T, Satoh H, Tamura K, Kasamatsu T, Hayashihara K, Saito T, Takahashi H, Ogura T. Metastatic brain tumors from non-small cell lung cancer with EGFR mutations: distinguishing influence of exon 19 deletion on radiographic features. Lung Cancer. 2012; 77:64-9.

18. Mak KS, Gainor JF, Niemierko A, Oh KS, Willers H, Choi NC, Loeffler JS, Sequist LV, Shaw AT, Shih HA. Significance of targeted therapy and genetic alterations in EGFR, ALK, or KRAS on survival in patients with nonsmall cell lung cancer treated with radiotherapy for brain metastases. Neuro Oncol. 2015; 17:296-302.

19. Russo A, Franchina T, Ricciardi GR, Ferraro G, Scimone A, Bronte G, Russo A, Rolfo C, Adamo V. Central nervous system involvement in ALK-rearranged NSCLC: promising strategies to overcome crizotinib resistance. Expert Rev Anticancer Ther. 2016; 16:615-23.

20. Falk AT, Poudenx M, Otto J, Ghalloussi H, Barrière J. Adenocarcinoma of the lung with miliary brain and pulmonary metastases with echinoderm microtubuleassociated protein like 4-anaplastic lymphoma kinase translocation treated with crizotinib: a case report. Lung Cancer. 2012; 78:282-4. 
21. Hayashi H, Okamoto I, Tanizaki J, Tanaka K, Okuda T, Kato A, Nishimura Y, Nakagawa K. Cystic brain metastasis in non-small-cell lung cancer with ALK rearrangement. J Clin Oncol. 2014; 32:e122-4.

22. Saraceni C, Li PM, Gainor JF, Stopyra GA, Friedman EL. Cystic Brain Metastases in NSCLC Harboring the EML4ALK Translocation after Treatment with Crizotinib. J Thorac Oncol. 2015; 10:1116-7.

23. Hasegawa M, Sakai F, Ishikawa R, Kimura F, Ishida H, Kobayashi K. CT Features of Epidermal Growth Factor Receptor-Mutated Adenocarcinoma of the Lung: Comparison with Nonmutated Adenocarcinoma. J Thorac Oncol. 2016; 11:819-26.

24. Yang Y, Yang Y, Zhou X, Song X, Liu M, He W, Wang H, Wu C, Fei K, Jiang G. EGFR L858R mutation is associated with lung adenocarcinoma patients with dominant groundglass opacity. Lung Cancer. 2015; 87:272-7.

25. Hsu JS, Huang MS, Chen CY, Liu GC, Liu TC, Chong IW, Chou SH, Yang CJ. Correlation between EGFR mutation status and computed tomography features in patients with advanced pulmonary adenocarcinoma. J Thorac Imaging. 2014; 29:357-63.

26. Kang HJ, Lim HJ, Park JS, Cho YJ, Yoon HI, Chung JH, Lee JH, Lee CT. Comparison of clinical characteristics between patients with ALK-positive and EGFR-positive lung adenocarcinoma. Respir Med. 2014; 108:388-94.

27. Biya J, Caramella C, Lindsay CR, Planchard D, Besse B. A Long-Term Spinal Intramedullary Response to Ceritinib in ALK Rearranged Non-Small-Cell Lung Cancer. J Thorac Oncol. 2015; 10:e44-5.

28. Franchina T, Russo A, Ricciardi GR, Liguori G, Herberg A, Normanno N, Adamo V. Long time response with chemotherapy in ROS1 NSCLC patient with unusual metastatic site. Cancer Biol Ther. 2016 Aug 12:1-5. [Epub ahead of print].

29. Rosell R, Carcereny E, Gervais R, Vergnenegre A, Massuti B, Felip E, Palmero R, Garcia-Gomez R, Pallares C, Sanchez JM, Porta R, Cobo M, Garrido P, et al. Erlotinib versus standard chemotherapy as first-line treatment for European patients with advanced EGFR mutation-positive non-small-cell lung cancer (EURTAC): a multicentre, open-label, randomised phase 3 trial. Lancet Oncol. 2012; 13:239-46.

30. Douillard JY, Ostoros G, Cobo M, Ciuleanu T, McCormack R, Webster A, Milenkova T. First-line gefitinib in Caucasian EGFR mutation-positive NSCLC patients: a phase-IV, open-label, single-arm study. Br J Cancer. 2014; 110:55-62.

31. Moro-Sibilot D, Smit E, de Castro Carpeño J, LesniewskiKmak K, Aerts JG, Villatoro R, Kraaij K, Nacerddine K, Dyachkova Y, Smith KT, Girvan A, Visseren-Grul C, Schnabel PA. Non-small cell lung cancer patients with brain metastases treated with first-line platinum-doublet chemotherapy: Analysis from the European FRAME study. Lung Cancer. 2015; 90:427-32.
32. Hsiao SH, Lin HC, Chou YT, Lin SE, Kuo CC, Yu MC, Chung CL. Impact of epidermal growth factor receptor mutations on intracranial treatment response and survival after brain metastases in lung adenocarcinoma patients. Lung Cancer. 2013; 81:455-61.

33. Gow CH, Chien CR, Chang YL, Chiu YH, Kuo SH, Shih JY, Chang YC, Yu CJ, Yang CH, Yang PC. Radiotherapy in lung adenocarcinoma with brain metastases: effects of activating epidermal growth factor receptor mutations on clinical response. Clin Cancer Res. 2008; 14:162-8.

34. Lee HL, Chung TS, Ting LL, Tsai JT, Chen SW, Chiou JF, Leung HW, Liu HE. EGFR mutations are associated with favorable intracranial response and progression-free survival following brain irradiation in non-small cell lung cancer patients with brain metastases. Radiat Oncol. 2012; $7: 181$.

35. Lee DW, Shin DY, Kim JW, Keam B, Kim TM, Kim HJ, Kim DW, Wu HG, Paek SH, Kim YW, Heo DS, Kim DG, Lee SH. Additional prognostic role of EGFR activating mutations in lung adenocarcinoma patients with brain metastasis: integrating with lung specific GPA score. Lung Cancer. 2014; 86:363-8.

36. Johung KL, Yao X, Li F, Yu JB, Gettinger SN, Goldberg S, Decker RH, Hess JA, Chiang VL, Contessa JN. A clinical model for identifying radiosensitive tumor genotypes in non-small cell lung cancer. Clin Cancer Res. 2013; 19:5523-32.

37. Lin JJ, Cardarella S, Lydon CA, Dahlberg SE, Jackman DM, Jänne PA, Johnson BE. Five-Year Survival in EGFRMutant Metastatic Lung Adenocarcinoma Treated with EGFR-TKIs. J Thorac Oncol. 2016; 11:556-65.

38. Zimmermann S, Dziadziuszko R, Peters S. Indications and limitations of chemotherapy and targeted agents in nonsmall cell lung cancer brain metastases. Cancer Treat Rev. 2014; 40:716-22.

39. Franceschi E, Bartolotti M, Poggi R, Di Battista M, Palleschi D, Brandes AA. The role of systemic and targeted therapies in brain metastases. Expert Rev Anticancer Ther. 2014; 14:93-103.

40. Heon S, Yeap BY, Lindeman NI, Joshi VA, Butaney M, Britt GJ, Costa DB, Rabin MS, Jackman DM, Johnson BE. The impact of initial gefitinib or erlotinib versus chemotherapy on central nervous system progression in advanced nonsmall cell lung cancer with EGFR mutations. Clin Cancer Res. 2012; 18:4406-14.

41. Jiang T, Su C, Li X, Zhao C, Zhou F, Ren S, Zhou C, Zhang J. EGFR TKIs plus WBRT Demonstrated No Survival Benefit Other Than That of TKIs Alone in Patients with NSCLC and EGFR Mutation and Brain Metastases. J Thorac Oncol. 2016 Oct;11:1718-28.

42. Liu S, Qiu B, Chen L, Wang F, Liang Y, Cai P, Zhang L, Chen Z, Liu S, Liu M, Liu H. Radiotherapy for asymptomatic brain metastasis in epidermal growth factor receptor mutant non-small cell lung cancer without prior 
tyrosine kinase inhibitors treatment: a retrospective clinical study. Radiat Oncol. 2015; 10:118.

43. Kim JE, Lee DH, Choi Y, Yoon DH, Kim SW, Suh C, Lee JS. Epidermal growth factor receptor tyrosine kinase inhibitors as a first-line therapy for never-smokers with adenocarcinoma of the lung having asymptomatic synchronous brain metastasis. Lung Cancer. 2009; 65:351-4.

44. Mulvenna P, Nankivell M, Barton R, Faivre-Finn C, Wilson P, McColl E, Moore B, Brisbane I, Ardron D, Holt T, Morgan S, Lee C, Waite K, et al. Dexamethasone and supportive care with or without whole brain radiotherapy in treating patients with non-small cell lung cancer with brain metastases unsuitable for resection or stereotactic radiotherapy (QUARTZ): results from a phase 3, non-inferiority, randomised trial. Lancet. 2016; 388:2004-2014.

45. Luo S, Chen L, Chen X, Xie X. Evaluation on efficacy and safety of tyrosine kinase inhibitors plus radiotherapy in NSCLC patients with brain metastases. Oncotarget. 2015; 6:16725-34. doi: 10.18632/oncotarget.4264.

46. Chen Y, Yang J, Li X, Hao D, Wu X, Yang Y, He C, Wang W, Wang J. First-line epidermal growth factor receptor (EGFR)-tyrosine kinase inhibitor alone or with whole-brain radiotherapy for brain metastases in patients with EGFRmutated lung adenocarcinoma. Cancer Sci. 2016 Sep 14. doi: 10.1111/cas.13079. [Epub ahead of print].
47. Magnuson WJ, Yeung JT, Guillod PD, Gettinger SN, Yu JB, Chiang VL. Impact of Deferring Radiation Therapy in Patients With Epidermal Growth Factor ReceptorMutant Non-Small Cell Lung Cancer Who Develop Brain Metastases. Int J Radiat Oncol Biol Phys. 2016; 95:673-9.

48. Kris MG, Johnson BE, Berry LD, Kwiatkowski DJ, Iafrate AJ, Wistuba II, Varella-Garcia M, Franklin WA, Aronson SL, Su PF, Shyr Y, Camidge DR, Sequist LV, et al. Using multiplexed assays of oncogenic drivers in lung cancers to select targeted drugs. JAMA. 2014; 311:1998-2006.

49. Barlesi F, Mazieres J, Merlio JP, Debieuvre D, Mosser J, Lena H, Ouafik L, Besse B, Rouquette I, Westeel V, Escande F, Monnet I, Lemoine A, et al. Routine molecular profiling of patients with advanced non-small-cell lung cancer: results of a 1-year nationwide programme of the French Cooperative Thoracic Intergroup (IFCT). Lancet. 2016; 387:1415-26.

50. Leighl NB, Rekhtman N, Biermann WA, Huang J, MinoKenudson M, Ramalingam SS, West H, Whitlock S, Somerfield MR. Molecular testing for selection of patients with lung cancer for epidermal growth factor receptor and anaplastic lymphoma kinase tyrosine kinase inhibitors: American Society of Clinical Oncology endorsement of the College of American Pathologists/International Association for the study of lung cancer/association for molecular pathology guideline. J Clin Oncol. 2014; 32:3673-9. 